\title{
Enhancing Gender Diversity in STEM Requires Support from All
}

\section{Dr. Keith J. Bowman, University of Maryland, Baltimore County}

Dr. Keith J. Bowman is Dean of the College of the College of Engineering and Information Technology (COEIT) and Constellation Professor of Information Technology and Engineering at UMBC, the University of Maryland, Baltimore County. Dr. Bowman began his academic career as a Purdue University Assistant Professor after receiving BS and MS degrees from Case Western Reserve University (CWRU) and a $\mathrm{PhD}$ degree in materials science and engineering from the University of Michigan. He served as a visiting professor and received Alexander von Humboldt stipends for research at the Technical University of Darmstadt, Germany in 1996 and 2002 and he served as a visiting professor at the University of New South Wales in Sydney, Australia in 2003. He is a Fellow of the American Ceramic Society and has held several division and society-wide positions. Awards at Purdue University include receiving the MSE Best Teaching Award and Purdue's highest teaching award, the Charles Murphy Undergraduate Teaching Award. Professor Bowman's name is also listed in the Purdue Book of Great Teachers. In 2007, he received the Purdue College of Engineering Mentoring Award and he became the first Professor of Engineering Education (by courtesy) from MSE. From 2007 to 2011 he served as Head of the Purdue School of Materials Engineering. In 2012 he was invested as the first Duchossois Leadership Professor in the Illinois Institute of Technology (IIT) Armour College of Engineering soon after joining as chair of Mechanical, Materials and Aerospace Engineering. Prior to UMBC he served two years as dean of the College of Science \& Engineering at San Francisco State University wherein he led more than four hundred faculty and staff and about six thousand majors.

\section{Prof. Sue Rosser, California State University System, Office of the Chancellor}

Sue Rosser has been Special Advisor for Academics, Research Development and External Partnerships at the California State University System Office of the Chancellor. From 2009-2016, she served as the Provost and Vice President for Academic Affairs at San Francisco State University since. From 1999 2009, she served as Dean of Ivan Allen College of Liberal Arts at Georgia Tech. She has published 14 books and more than 140 journal articles on the theoretical and applied issues surrounding women and gender in science, health and technology. 


\title{
Enhancing Gender Diversity in STEM Requires Support from All
}

\begin{abstract}
Professor Barbara Oakley of Oakland University recently attributed part of the responsibility for limited science, technology, engineering and mathematics (STEM) diversity to faculty from the humanities and social sciences who "malign" STEM disciplines and characterize STEM careers as unworthy of literate and creative individuals. The gap between the depiction of a STEM person and their own identity is seen as an obstacle for women and other underrepresented individuals to development of their own STEM identity. Substantial research on curricular, co-curricular and extra-curricular interventions and pedagogical strategies designed to elevate students' STEM identities and their likelihood of pursuing STEM careers ties to efforts to foster a STEM identity permitting all students to see themselves as a "STEM kind of person".

Larger increases in the number of bachelor's degrees earned by women and distribution across disciplines have changed gender diversity for both STEM and non-STEM disciplines. One contributing factor is that bachelor's degrees earned by American women have more than tripled since 1970, while those for men only increased by about sixty percent, although wide variance exists in gender distribution across the disciplines in both STEM and non-STEM fields, with the extreme being computer science where women earn less than $20 \%$ of bachelor's degrees. Although in 2016 US men earned only $22 \%$ of psychology bachelor's degrees, $30 \%$ of Englishliterature bachelor's degrees, and less than $20 \%$ of education bachelor's degrees, significant concern over the lack of males in some areas of study and careers is rarely expressed. With the increasing influence of engineering design and computing in shaping our lives, education standards should require all students to have significant and equitable STEM experiences. Such a requirement would foster an interest in STEM subjects and careers in more, diverse students, while reducing the focus on STEM pipelines.
\end{abstract}




\section{Introduction}

As a response to a recent essay from Lecturer Stuart Reges on "Why Women Don't Code," [1] Professor Barbara Oakley of Oakland University supported his premise that women often choose non-STEM disciplines, but attributed part of the responsibility for limited science, technology, engineering and mathematics (STEM) diversity to faculty from the humanities and social sciences who "malign" STEM disciplines and characterize STEM careers as unworthy of literate and creative individuals [2]. Does she have a good point? During the last two decades substantial effort has been expended towards reconciling developing students with what can be broadly defined as STEM identities. Considerable recent research broadly on STEM identities [e.g. 3-21], including separate considerations of science, engineering and math identities, has focused on the identities of groups and intersectionalities underrepresented in STEM disciplines and careers. But, some research also suggests that merely inserting a STEM label, e.g. science or scientist, into a discussion unleashes implicit biases of gender, race and ethnicity in middle school children [14].

Surveys to assess self-efficacy and science identity in children and young adults are frequently juxtaposed against knowledge and interest in particular STEM careers [22-24]. Researchers interested in understanding stereotypes held by young children of STEM professionals have evolved Draw-a-Person tests to include asking students to draw scientists, mathematicians and engineers [25-29]. Despite the use of different methodologies, STEM identity research on promoting inclusivity consistently shows that students, at least those from Western countries, are likely to describe STEM professionals as unattractive, asocial and disheveled white males. The gap between this depiction of a STEM person and their own identity is seen as an obstacle for women and other underrepresented individuals towards development of their own STEM identity. Substantial research on curricular, co-curricular and extra-curricular interventions and pedagogical strategies designed to elevate students' STEM identities and their likelihood of pursuing STEM careers ties to efforts to foster a STEM identity permitting all students to see themselves as a "STEM kind of person"[23].

Critical to advancing equity is exploring the role that all academic disciplines have in shaping the gender diversity of the workforce, both STEM and non-STEM. But, there is also a challenge in even defining the categories that comprise STEM. With the increasing influence of engineering design and computing in shaping our lives, education standards likely should require all students to have significant and equitable STEM experiences. Such a requirement could foster an interest in STEM subjects and careers in more, diverse students, while reducing the focus on STEM pipelines. This would parallel the situation in some other countries where the college track requires all students to follow the same curriculum, regardless of gender. In another way, it would align with education in the humanities and social sciences where the focus is not explicitly on careers and pipelines, but on knowledge. Harvey Mudd College has had success in reaching gender parity in computer sciences by starting first year students at the same place, making certain that all take Introduction to Computer Science, thereby eliminating the effect of women feeling less prepared because of prior experience males may have gleaned from tinkering with computers as teens [30]. The first-year course also integrates discussions of societal and ethical issues related to computer science. Larger increases in the number of bachelor's degrees earned by women and distribution across disciplines have remarkably changed gender diversity for a number of disciplines. This ultimately produces some disciplines that are criticized for low participation of women and relatively slow progress and others where an equivalent and declining participation of men garners 
relatively little attention or action. It seems possible that focusing on careers for some disciplines, and not for others, may in itself change the perception of those topics for students who will ultimately find careers in either STEM or non-STEM areas. The focus on careers may also not be practical, given predictions that most young people will have twelve to fifteen jobs in their lifetime. The median number of years that wage and salary workers had been with their current employer was 4.2 years in January, 2018. [32].

Studies have shown that although the social value of a particular career varies from society to society, what men do tends to be valued more highly than what women do and in most countries a gender gap exists in pay with women earning less than men within the same occupation, with an unexplained wage gap due to discrimination of $12-20 \%$ internationally [33]. In the U.S. the gender gap in pay averaged $22 \%$ in 2018 [34]. Overall, socialization reinforces stereotypes, and gender may be a powerful force motivating an individual to choose or avoid a particular career, despite excellent job opportunities and salaries. Just as women have tended to avoid certain majors and careers such as computer science and engineering, despite demand and compensation, men have avoided fields such as nursing and health care, despite increasing salaries and job opportunities. In this paper, we provide a historical perspective on the evolution of several large and changing disciplines with a focus on gender segregation as documented by the National Center for Education Statistics (NCES). The implications of increasing gender segregation in some disciplines and potential approaches to reduce gender segregation are discussed.

\section{Analysis}

Today, nearly twenty percent of Americans over eighteen years old have an earned bachelor's degree. Due to women's greater longevity, the population over eighteen has seven percent more female-identified Americans than male-identified Americans. But, during the last forty years, an even more significant increase in bachelor's degree attainment for women has led to women with bachelor's degrees outnumbering men by thirteen percent. Women hold 26 million bachelor's degrees versus $\sim 23$ million bachelor's degrees held by men. The striking change from 1970 to 2016 is shown in Table 1 [35].

Table 1 Bachelor's Degrees by Gender
\begin{tabular}{|r|c|c|}
\hline Year & Female & Male \\
\hline $\mathbf{1 9 7 0}$ & 341,219 & 451,097 \\
\hline $\mathbf{2 0 1 6}$ & $1,082,276$ & 812,693 \\
\hline Change & $217.2 \%$ & $80.2 \%$ \\
\hline
\end{tabular}

Defining and advancing STEM diversity is an increasingly complicated endeavor that requires a renewed consideration of how we quantitatively and qualitatively define success. For example, a growing number of individuals identify in new and distinct ways relative to the traditional gender, race or ethnicity boxes demographers have employed. For the moment, but likely just so, quantitative data shows sufficient rates of participation due to US federal mandates requiring an expanded number of categories tracked by institutions, making it still possible to undertake some coherent assessments. Intriguing aspects of how we communicate about diversity in STEM include failing to connect diversity in STEM to diversity in non-STEM disciplines within the context of the remarkable difference in degree growth for women versus men. Equally intriguing is whether 
we are all using a common definition for the disciplines that comprise STEM. As with many things we may take for granted, different outcomes result depending upon who does the defining.

\section{Different Definitions of STEM}

For a period of time prior to 2001, the definition for STEM used by the US National Science Foundation (NSF) relied upon a different order of the same words that comprise STEM, leading to a variety of acronyms, including SMET and METS [36]. Table 2 shows a list of NCES, a database used throughout this paper, with disciplines in the categories assigned by NSF [35]. For our purposes, business degrees will be treated as a special category of non-STEM degrees.

Table 2 NSF STEM, Non-STEM and Business Definitions using 2017 NCES Disciplines

\begin{tabular}{|c|c|c|}
\hline STEM & Non-STEM & Business. \\
\hline Agriculture and natural resources & Area, ethnic, cultural, gender, and group studies & Business. \\
\hline Architecture and related services & Communication, journalism, and related programs & \\
\hline Biological and biomedical sciences & Communications technologies & \\
\hline Computer and information sciences & Education & \\
\hline Construction trades & English language and literature/letters & \\
\hline Engineering & Family and consumer sciences/human sciences & \\
\hline Engineering technologies and engineering-related fields & Foreign languages, literatures, and linguistics & \\
\hline Mathematics and statistics & Health professions and related programs & \\
\hline Mechanic and repair technologies/technicians & History & \\
\hline Military technologies and applied sciences & Homeland security, law enforcement, and firefighting & \\
\hline Physical sciences and science technologies & Legal professions and studies & \\
\hline Psychology & Liberal arts and sciences, general studies, and humanities & \\
\hline Social sciences & Library science & \\
\hline \multirow[t]{7}{*}{ Transportation and materials moving } & Multi/interdisciplinary studies & \\
\hline & Parks, recreation, leisure, and fitness studies & \\
\hline & Philosophy and religious studies & \\
\hline & Public administration and social services & \\
\hline & Theology and religious vocations & \\
\hline & Visual and performing arts & \\
\hline & Other and not classified & \\
\hline
\end{tabular}

In various ways, a number of individuals, including Judith Ramaley, Rita Colwell, Peter Faletra and Charles Vela have been credited for the transition to STEM as the preferred acronym, but Charles Vela is likely the earliest to promote the acronym when under his leadership the Center for Advancement of Hispanics in Science and Engineering began a STEM Institute at the Catholic University of America in 1992 [36-38]. Contemporaneously with STEM education becoming defined as an area of critical need, concerns over the availability of skills and knowledge for the labor force have resulted in STEM disciplines being privileged specifically for the recruiting of international workers. Thus, U.S. Immigration and Customs Enforcement maintains its own list of STEM disciplines that does not include many social sciences, but does include many medicallyrelated professions if they are research-related [39]. The National Institutes of Health has also defined disciplines associated with the research workforce with doctorates in behavioral, clinical and biomedical fields, but strongly emphasizes doctoral level education [40].

Recently, Xie, Fang and Shauman provided a fairly robust statement defining STEM education and distinguishing it from how we typically define general education for university degrees [41]: 
"STEM education is special because it is required for science or engineering employment. While it is possible, indeed common, for someone with STEM education to pursue a career outside of science and engineering, it is very difficult for someone without STEM education to pursue a career in STEM. There are good reasons to believe that the social determinants of STEM education, like the determinants of science careers, are different from those of general education."

Xie, Fang and Shauman also noted that the concept of STEM varies depending upon the level of education. Although they are correct that for the elementary school level, historically, science and math were the defining attributes of STEM, the introduction of the Next Generation Science Standards resulted in education standards that included engineering design [42]; a number of states are evolving efforts that will result in specific education practices and standards developed for computing [43]. That approach has resulted in changes in pre-teacher and teacher education across a number of states. Still, they correctly indicate that distinct STEM disciplines become increasingly relevant at higher and higher levels of education as students progress through high school to college with specific science topics such as biology, psychology, chemistry and physics becoming defined courses.

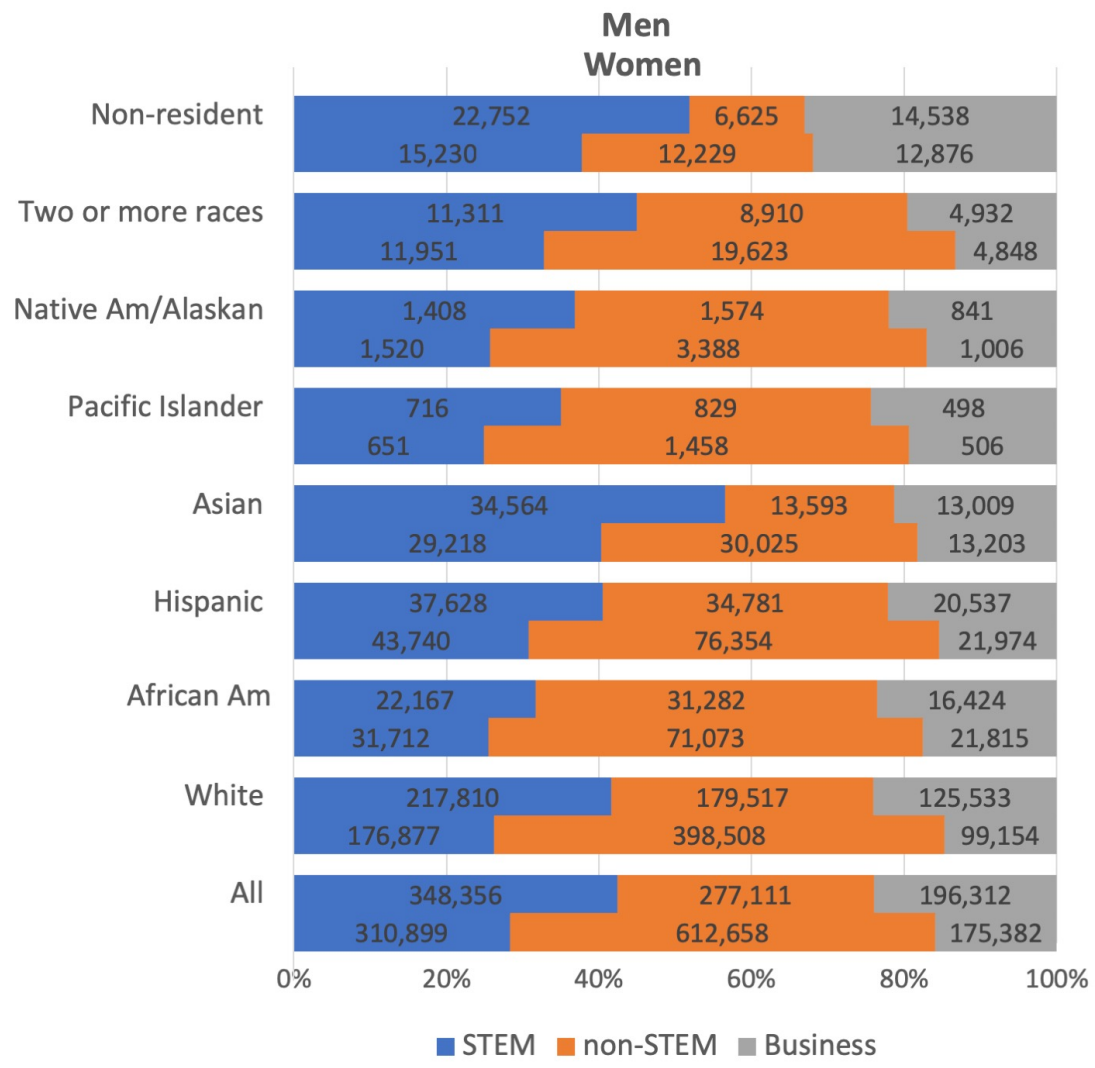

Figure 1 STEM, non-STEM and business degrees for National Council on Education Statistics classifications using US National Science Foundation definitions for 2015-2016. The number of degrees for each case is also given. The upper part of the bar indicates degrees earned by men and the lower part of each bar indicates degrees earned by women. 
Figure 1 shows the gender distribution by race and ethnicity for STEM, non-STEM and business degrees from 2015-2016 NCES data. The definitions for STEM and non-STEM use the NSF categories from Table 1 . In every category the fraction of female degree recipients receiving a STEM or business degree is lower than that for males. Looking a bit closer at the numbers provides some added insight and takes into account the larger number of degrees being earned by women. Using NSF definitions, the number of degrees earned by women in STEM among African Americans, Hispanic Americans, Native and Alaskan Americans and individuals choosing two or more races outnumber those earned by men. Using the NSF definitions for STEM, women comprise $47 \%$ of the degrees earned in STEM professions. On the other hand, for NSF non-STEM degrees women outpace men by a factor of two. We find it striking that one simple change in the NCES data produces a modification of Figure 1 that is at least viscerally close to the gender parity many are seeking. Most health professions, including nursing and pharmacy, do require significant STEM training in mathematics, physical sciences, biology and psychology, but they are typically not included in definitions of STEM. Consider what happens when the NCES category of "Health Professions" is added to the NSF-defined STEM disciplines shown in Figure 2.

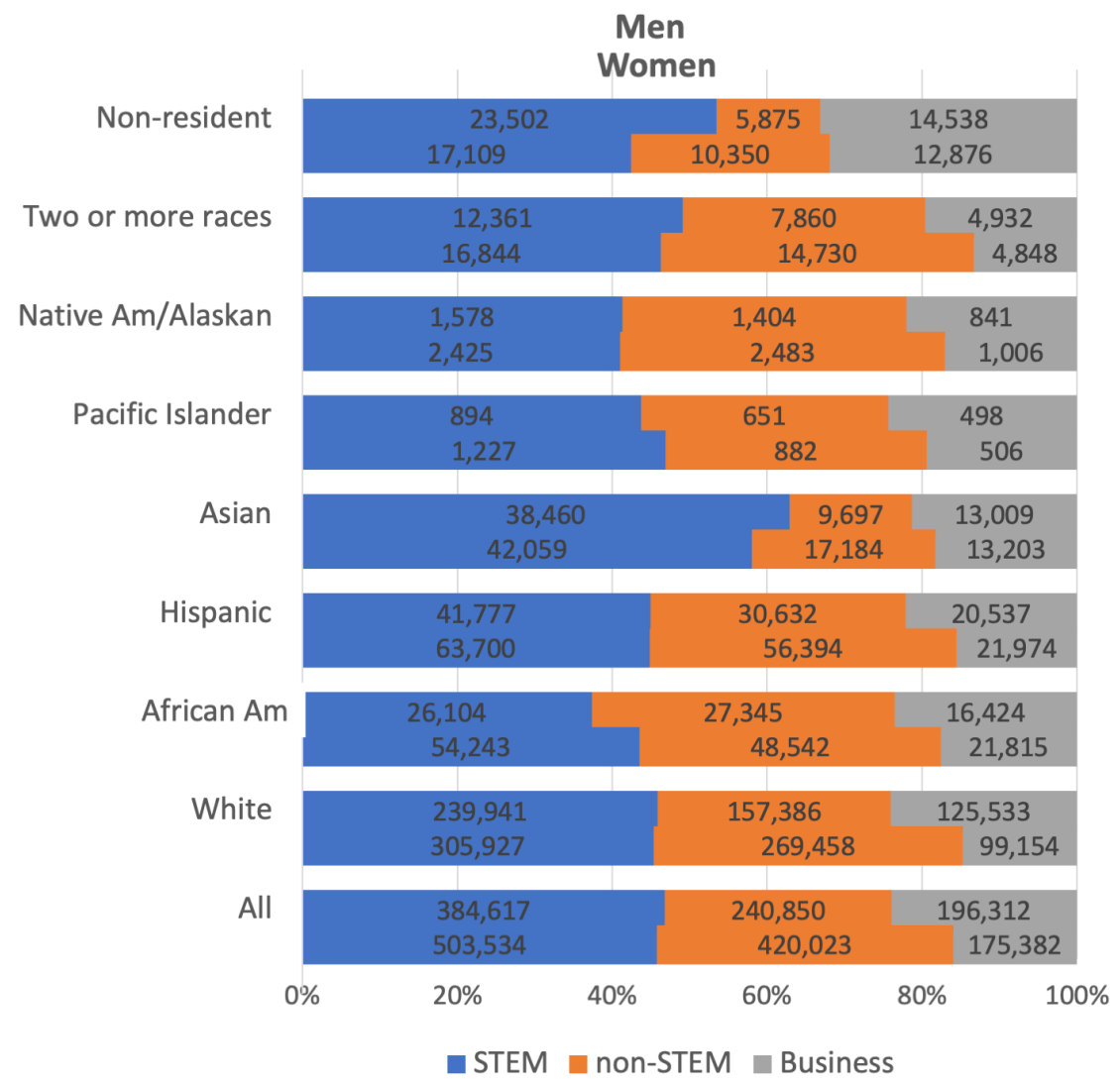

Figure 2 STEM, non-STEM and business degrees for National Council on Education Statistics classifications using US National Science Foundation definitions for 2015-2016, but moving Health Professions from non-STEM to STEM. The number of degrees for each case is also given. The upper part of the bar indicates degrees earned by men and the lower part of each bar indicates degrees earned by women. 
The definition for STEM used in Figure 2 produces a STEM degree fraction that is fairly consistent from category to category at just over $40 \%$ for women and men for most race and ethnic groups. Asian Americans show a notably higher number of degrees, approaching $60 \%$ for women and men, with Asian American women just a small percentage lower as STEM degree recipients, and African American men lagging all groups. Using this definition, women greatly outnumber men in every category. The result in Figure 2 is only possible because of very strong gender segregation, female and male, across many disciplines, especially in health professions.

Table 3 parallels Table 1 in showing the changes since 1970 for six gender-segregated degree areas, Psychology, Education, English, Computing, Engineering and Health Professions, that have resulted in the data presented in Figures 1 and 2. The profound changes in some disciplines are related to the increasing importance of some fields as advances in STEM research lead to innovations that have transformed our lives. A comparison between 2016 and 1970 shows that the number of women receiving degrees in computing, which was initially about one sixth that of men, has increased by a factor of thirty-seven times, while degrees for men have increased by twentyfive times. The result is that male degrees in computing outpaced female degrees by about 4.3 times in 2016. In 1970, less than one percent of engineering degrees were earned by women; since then the number of women earning degrees has increased by nearly sixty times, while degrees for men have only doubled. The result is that in 2016 male degrees in engineering outpaced female degrees by about 4.1 times. Both computing and engineering degree production shows an overall upward trend and has become less segregated across this time period.

Table 3 Bachelor's Degrees by Gender for Six Disciplinary Areas by Number

\begin{tabular}{|r|r|r|r|r|r|r|}
\hline & \multicolumn{2}{|c|}{ Psychology } & \multicolumn{2}{|c|}{ Education } & \multicolumn{2}{|c|}{ English } \\
\hline Year & Female & Male & Female & Male & Female & Male \\
\hline 1970 & 16,960 & 21,227 & 131,411 & 44,896 & 41,909 & 22,005 \\
\hline 2016 & 91,161 & 26,279 & 69,790 & 17,427 & 30,019 & 12,776 \\
\hline Change & $437.5 \%$ & $23.8 \%$ & $-46.9 \%$ & $-61.2 \%$ & $-28.4 \%$ & $-41.9 \%$ \\
\hline & Computing & Engineering & Health \\
\hline Year & Female & Male & Female & Male & Female & Male \\
\hline 1970 & 324 & 2,064 & 407 & 49,775 & 19,438 & 5,785 \\
\hline 2016 & 12,072 & 52,333 & 24,381 & 99,628 & 192,635 & 36,261 \\
\hline Change & $3625.9 \%$ & $2435.5 \%$ & $5890.4 \%$ & $100.2 \%$ & $891.0 \%$ & $526.8 \%$ \\
\hline
\end{tabular}

In 1970, psychology degrees earned by men surpassed those earned by women by nearly twentyfive percent. Since then, psychology degrees for women have increased by about a factor of five while degrees for men have increased only twenty-four percent. The result is that in 2016 women earned 3.5 times more bachelor's degrees in psychology than men did. Degrees in both Education 
and English, disciplines wherein women have long outnumbered men, have declined since 1970, but the percent decline in degrees has been greater for men than for women. In 1970, degrees earned by women in education and English outpaced degrees earned by men by 2.9 and 1.9 times, respectively. By 2016, the female-to-male degree ratios for education and English have increased 4.0 and 2.3 times, respectively.

Like education and English, health professions have long been female-dominated degrees. But, unlike education and English degrees, health professions have seen very strong growth for women and for men, with degrees having increased nearly tenfold for women and sixfold for men. But, that difference in growth has also caused the female-to-degree ratio to increase from 3.4 to 5.3 times, making health professions the most gender-segregated of the disciplinary areas given in Table 3.

Table 4 Female Fraction of Bachelor's Degrees from 1970 to 2016

\begin{tabular}{|r|c|c|c|c|c|c|}
\hline Year & Psychology & Education & English & Computing & Engineering & Health \\
\hline $\mathbf{1 9 7 0}$ & 0.44 & 0.75 & 0.66 & 0.14 & 0.01 & 0.77 \\
\hline $\mathbf{2 0 1 6}$ & 0.78 & 0.80 & 0.70 & 0.19 & 0.20 & 0.84 \\
\hline
\end{tabular}

Figure 3 shows the trends in degree growth in the six disciplines for US women and men since 1970. This set of degrees shows the scaling and trends for each of these disciplines by gender. The growth in health degrees, particularly for women, across the past fifteen years is quite striking as are the declines in some fields. Trends for computing degrees are particularly interesting since considerable discussion still occurs about the early 2000s dot-com bust and its impact on computing degrees; this data shows that a similar decline occurred in the mid-eighties.
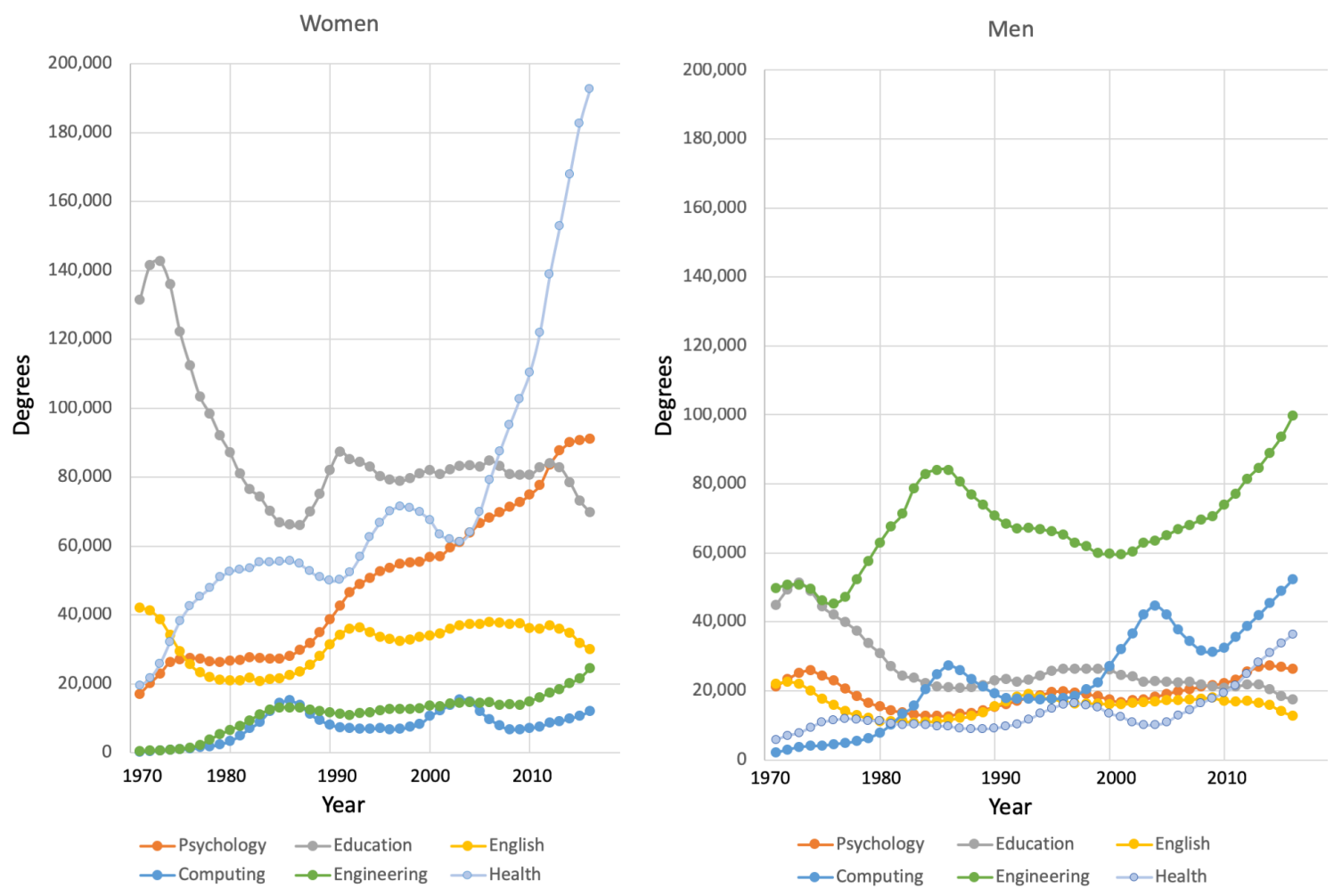
Figure 3 Bachelor's Degree Production for Women and Men from 1970 until 2016 for Six Strongly Gender-Segregated Disciplines

Figure 4 shows the female and male fractions for each of the six disciplines in Figure 3 . Both are shown to demonstrate the clear similarity in the extent of gender segregation for the female- and male-dominated disciplines. Figure 4 also shows that all six of the disciplines except for computing have had fairly monotonic changes in degree gender equity from 1970 to 2016. From 1970 until the early 1980s, computing degrees were on track towards gender equity. Following each of the periods when computing degrees overall have peaked, the subsequent increase in degrees received by men has proceeded at a higher rate than the recovery for degrees received by women. The peak of women's obtaining bachelor's degrees in computing was 37\% which occurred in 1984-85 [44].
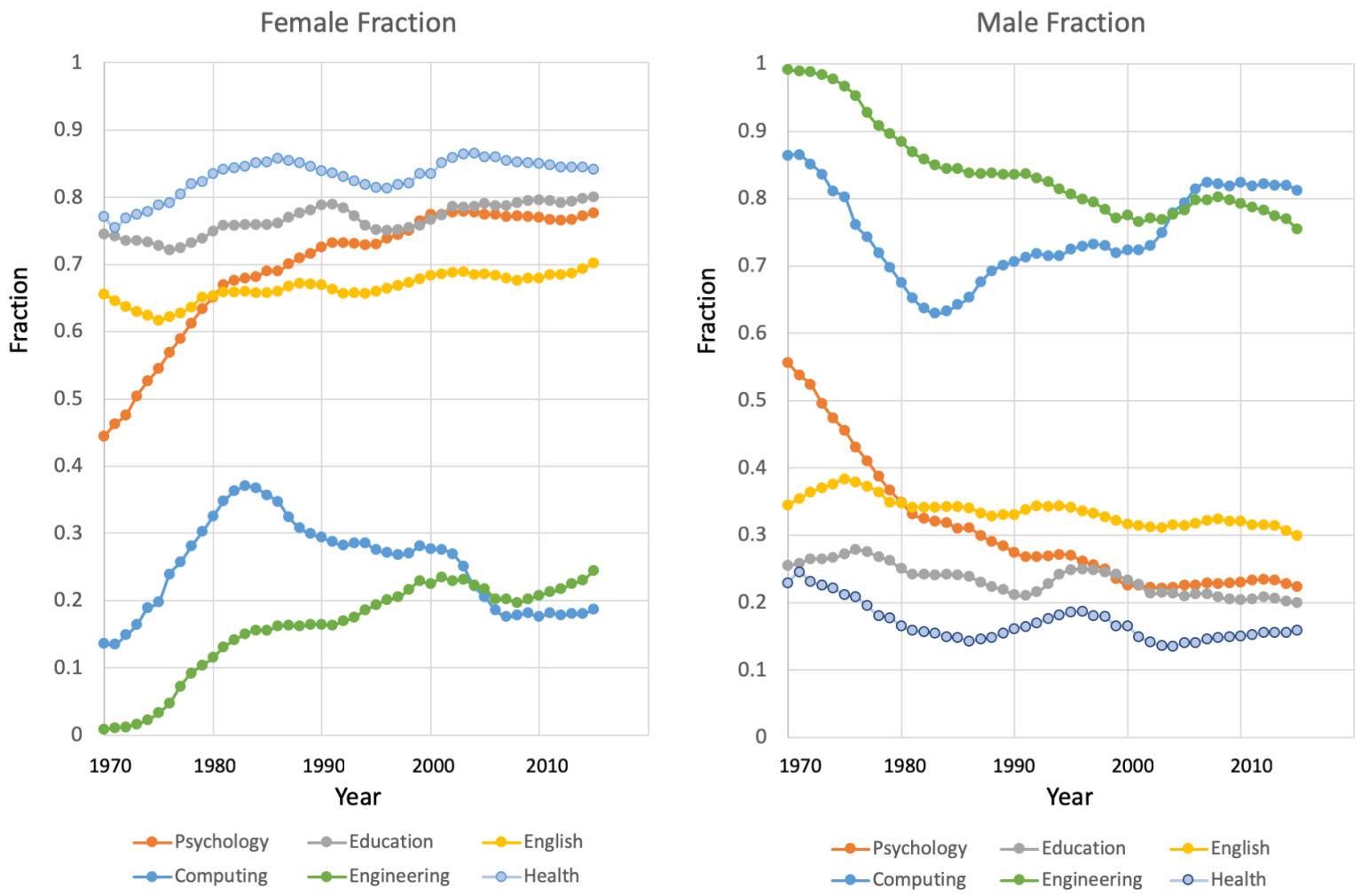

Figure 4 Bachelor's Degree Gender Segregation for Women and Men from 1970 until 2016 for Six Disciplines

\section{Discussion}

The persistent challenge of advancing gender diversity in some disciplines is well-documented for some physical sciences, engineering and computing. Concurrently, in 2016 US men earned only $22 \%$ of psychology bachelor's degrees, 30\% of English-literature bachelor's degrees, and less than $20 \%$ of education bachelor's degrees. Yet, significant concern over the lack of males in some areas of study and careers is rarely expressed. Does this suggest that we should have an interest, and maybe a mandate, to seek and promote diversity in all disciplines, thereby ensuring equity and achievement of full creative potential? The data shown in this paper demonstrate that computing and engineering have made considerable progress in becoming more gender diverse, even if the 
progress has not always been on a consistent trend for computing. In contrast, several important and large disciplinary areas are on course to continue becoming less gender diverse, as they become increasingly tilted towards more women receiving degrees. Ready arguments to express strong concern for reducing male dominance of computing and engineering can be made aligned with the high demand and projected continued high demand for STEM degrees and competitive levels of compensation. But, one of the hallmark arguments made for diversity in a business context is that better and more creative solutions will result if innovations are more broadly inclusive. Health professions represent an area where demographic shifts in the overall population and retirement of current professionals drives extreme demand. Some of the professions such as nursing have traditionally been female-dominated, while others such as pharmacy, have shifted from traditional male-domination to now being female-dominated. Although time flexibility, possibility for employment in both rural and urban settings, and relatively good salaries characterize these health professions, they remain and are becoming, increasingly femaledominated. Even in parts of the country with higher rates of unemployment, men eschew training and careers in these health professions, presumably because of their focus on service and history of female participation.

As previously described above, computing and engineering topics were not traditionally included in elementary education. Their introduction across the past decade has been strongly tied to preparing students for careers. As is evident from Draw-a-Scientist or Draw-a-Mathematician research [25-27], young people already recognized that science and math provided more than skills and knowledge; they are very relevant to having careers. Perversely, exactly the same education topics that have not been emphasized to young students as important for career success have become the "soft skills" sought by employers for computing and engineering professionals.

Recently, a number of institutions have developed courses, or in some cases even majors or minors (Stanford, Illinois, Northwestern etc.), generically referred to as CS+X, or computer science plus another discipline [45-47]. The University of California, Berkeley's version of this is a new Bachelor of Arts degree in Data Science [48]. The University of British Columbia's bachelor of arts degree in computer science [49] serves as an early example of CS+X; it typically begins with a foundational education in computer science followed by an emphasis on upper division humanities and social sciences to ensure that computer science majors learn communication, psychology, social organization and behavior, ethics, and other "soft skills". These CS $+\mathrm{X}$ programs broaden the educational context and exposure to the liberal arts often missing in traditional majors in CS and engineering. Ironically, the absence of this broader focus on making a difference on a human level, as emphasized in humanities and social sciences, represents a primary reason women give for not choosing computer science or engineering as a major [44]. $\mathrm{CS}+\mathrm{X}$ programs have some similarity to the approach used at Dartmouth University for students majoring in engineering sciences [50]. All successful engineering sciences majors earn a bachelor of arts degree with additional courses required to complete the professional bachelor of engineering degree. There are then numerous options for adding engineering sciences to liberal arts degrees. Dartmouth has reported substantial success in diversifying engineering [51] This approach could be categorized as a type of Engineering $+X$. Dartmouth's approach is derivative of the hybrid $3+2$ liberal arts - engineering degree programs that have long existed at some institutions or across partner institutions where a liberal arts junior earns a professional engineering degree along with a degree in liberal arts after completing the course of study. What seems quite 
different is the success in producing a larger number of diverse graduates than has previously been demonstrated for some highly selective private universities. It remains to be seen whether this can be replicated at larger institutions that admit a much broader cross-section of students that may enter college with lower levels of mathematics proficiency.

In an attempt to attract more diversity, including gender diversity, to CS, some institutions have also begun to experiment with adding some courses in computer science to traditional humanities and social sciences majors. Some of these institutions may have also seen that implementing a successful $\mathrm{CS}+\mathrm{X}$ curriculum creates burdens for students that can limit success. Although their experiment in $\mathrm{CS}+\mathrm{X}$ has been widely promoted, Stanford recently announced that it is abandoning its $\mathrm{CS}+\mathrm{X}$ pilot program, although reasons for its failure have also been attributed to poor implementation [52].

Alternatives to $\mathrm{CS}+\mathrm{X}$ have been developed as an approach to attract more women to CS by taking computing to where the women have demonstrated an interest by their presence, e.g. humanities, social sciences and biology; these courses, majors or minors can be characterized as X+CS or $\mathrm{X}+$ Computing. The Promoting Inclusivity in Computing (PINC) program at San Francisco State University exemplifies such a $\mathrm{X}+\mathrm{CS}$ initiative where computing expertise is offered to female students in majors such as biological sciences where they already are fairly abundant [53]. Students who may have chosen to limit their math and computing have discovered that the computational tools used for simulations and genetics enable them to more deeply engage with their existing interest in ecology or biology. PINC is one of six programs that are part of the Technology Pathways Initiative (TPI) of the Center for Advancing Women in Technology [54] TPI is targeted at integrating computing education for students in STEM disciplines that already have high female enrollment. The University of Maryland, Baltimore County (UMBC) also recently began a new $\mathrm{X}+\mathrm{CS}$ program with NSF funding [55] that utilizes UMBC's existing infrastructure for students choosing Individualized Studies as their chosen degree program.

Perhaps these $\mathrm{CS}+\mathrm{X}$ and $\mathrm{X}+\mathrm{CS}$ approaches will increase both the numbers of women in CS and the numbers of men in humanities and social sciences. In addition, they may demonstrate to both the students and faculty in the humanities, social sciences, sciences and engineering, including CS, that all fields need literate, creative individuals to prepare for the evolving careers needed to keep the US competitive in our global society. Alternatives to these approaches may have been left on the sidelines, as we consider how computing and engineering design "fit" into education at all levels. Some challenges may include very intense focus on the discipline of computer science at the expense of broader consideration of computing education. Since it is inevitable that all of our disciplines will become data intensive, the emphasis on computer science education may have allowed us to ignore the important roles of data-intensive disciplines such as statistics [56] and information systems (or iSchools) [57].

Recent announcements of new colleges of computing [58], or data science [59] may really be an interim step towards a more complete transformation of university education. Some institutions, such as Georgia Tech and the Naval Academy already require students from all majors to take at least one computing-related course as part of their required degree requirements [60,61]. Another clear step that would ensure that all individuals who graduate from a four-year institution are prepared to be full participants in society could be general education requirements in computing 
and engineering design. That also would require rethinking the role of most engineering and computing colleges and programs to include offering service courses for all majors. These recalibrations, both philosophical and financial, might make the more respectful perspectives sought by Professor Oakley possible. It is also possible that treating computing and engineering design as foundational parts of an education, rather than just as vehicles towards vocations might also provide benefits in having our society realize that these topics are important beyond vocational emphases [62]. STEM education must be recognized not only as important for a few STEMspecific disciplines, but also for people from all backgrounds, concurrent with the realization of the importance of having people of all gender identities, sexualities, races, ethnicities and social backgrounds well-represented in all disciplines. In that way, we might ensure that a stronger STEM identity can be developed for all.

\section{References}

[1] S. Reges. "Why Women Don't Code," Quillette, June 19, 2018 [Online]

https://quillette.com/2018/06/19/why-women-dont-code/ [Accessed January 14, 2019].

[2] B. Oakley. "Why do Women Shun STEM? It's Complicated," Wall Street Journal, July 13, 2018 [Online] https:/www.wsj.com/articles/why-do-women-shun-stem-its-complicated1531521789 [Accessed January 14, 2019].

[3] J. Steinke. "Adolescent girls' STEM identity formation and media images of STEM professionals: Considering the influence of contextual cues." Frontiers in Psychology 8 (2017): 716.

[4] K. H. Collins. "Confronting Color-Blind STEM Talent Development: Toward a Contextual Model for Black Student STEM Identity." Journal of Advanced Academics 29.2 (2018): 143168.

[5] S. L. Kuchynka, K. Salomon, J. K. Bosson, M. El-Hout, E. Kiebel, C. Cooperman, and R. Toomey. "Hostile and Benevolent Sexism and College Women's STEM Outcomes." Psychology of Women Quarterly 42.1 (2018): 72-87.

[6] K. Rainey, M. Dancy, R, Mickelson, E. Stearns, \& S, Moller. "Race and gender differences in how sense of belonging influences decisions to major in STEM." International Journal of STEM Education 5, no. 1 (2018): 10.

[7] S. L. Rodriguez, C. Lu, \& M. Bartlett. "Engineering Identity Development: A Review of the Higher Education Literature" International Journal of Education in Mathematics, Science and Technology, 6(3), (2018): 254-265. 
[8] J. R. Moreloc., "A systematic literature review of engineering identity: definitions, factors, and interventions affecting development, and means of measurement." European Journal of Engineering Education, 42(6), (2017):1240-1262.

[9] B. M. Capobianco, E. D. Deemer, \& C. Lin. “Analyzing Predictors of Children’s Formative Engineering Identity Development" International Journal of Engineering Education, 33(1), (2017): 44-54.

[10] C. Frieze, J. L. Quesenberry, E. Kemp, \& A. Velázquez. "Diversity or difference? New research supports the case for a cultural perspective on women in computing." Journal of Science Education and Technology 21, no. 4 (2012): 423-439.

[11] B. M. Capobianco, B. F. French, \& Heidi Diefes-Dux. "Engineering identity development among pre-adolescent learners." Journal of Engineering Education 101, no. 4 (2012): 698-716.

[12] J. Abbiss, Jane. "Boys and machines: gendered computer identities, regulation and resistance." Gender and Education23, no. 5 (2011): 601-617.

[13] N. Ensmenger, "“Beards, Sandals, and Other Signs of Rugged Individualism": Masculine Culture within the Computing Professions." Osiris 30, no. 1 (2015): 38-65.

[14] P. W. Hill, J. McQuillan, A. N. Spiegel, \& J. Diamond. "Discovery Orientation, Cognitive Schemas, and Disparities in Science Identity in Early Adolescence." Sociological

Perspectives 61, no. 1 (2018): 99-125.

[15] A. Byars-Winston, J. Rogers, J. Branchaw, C. Pribbenow, R. Hanke, \& C. Pfun. "New measures assessing predictors of academic persistence for historically underrepresented racial/ethnic undergraduates in science." CBE_Life Sciences Education 15, no. 3 (2016): ar32.

[16] M-C. Shanahan. "Identity in science learning: Exploring the attention given to agency and structure in studies of identity." Studies in Science Education 45, no. 1 (2009): 43-64.

[17] A. N. Spiegel, J. McQuillan, P. Halpin, C. Matuk, \& J. Diamond. "Engaging teenagers with science through comics." Research in Science Education 43, no. 6 (2013): 2309-2326.

[18] A. Chapman, \& Allan Feldman. "Cultivation of science identity through authentic science in an urban high school classroom." Cultural Studies of Science Education 12, no. 2 (2017): 469491.

[19] E. Skinner, Ellen, E. Saxton, C. Currie, \& G. Shusterman. "A motivational account of the undergraduate experience in science: brief measures of students' self-system appraisals, engagement in coursework, and identity as a scientist." International Journal of Science Education 39, no. 17 (2017): 2433-2459.

[20] K. I. Maton, T. S. Beason, S. Godsay, M. R. Sto. Domingo, T. C. Bailey, S Sun, \& F. A. Hrabowski III. "Outcomes and processes in the Meyerhoff scholars program: STEM PhD 
completion, sense of community, perceived program benefit, science identity, and research selfefficacy." CBE-Life Sciences Education 15, no. 3 (2016): ar48.

[21] D. Radovic, L. Black, J. Williams, \& C. E. Salas. "Towards conceptual coherence in the research on mathematics learner identity: a systematic review of the literature." Educational Studies in Mathematics 99, no. 1 (2018): 21-42.

[22] V. Sawtelle, E. Brewe, \& L. H. Kramer. "Exploring the relationship between self-efficacy and retention in introductory physics." Journal of Research in Science Teaching 49, no. 9 (2012): 1096-1121.

[23] G. Trujillo, \& K. D. Tanner. "Considering the role of affect in learning: Monitoring students' self-efficacy, sense of belonging, and science identity." CBE—Life Sciences Education 13, no. 1 (2014): 6-15.

[24] A. M. Flowers III, \& Rosa Banda. "Cultivating science identity through sources of selfefficacy." Journal for Multicultural Education 10, no. 3 (2016): 405-417.

[25] D. W. Chambers. "Stereotypic images of the scientist: The Draw-a-Scientist Test." Science Education 67, no. 2 (1983): 255-265.

[26] S. Losh, R. Wilke, \& M. Pop. "Some methodological issues with "Draw a Scientist Tests" among young children." International Journal of Science Education30, no. 6 (2008): 773-792.

[27] S. H. Picker, \& J. S. Berry. "Investigating pupils' images of mathematicians." Educational Studies in Mathematics 43, no. 1 (2000): 65-94.

[28] M. Knight, \& C. Cunningham. "Draw an engineer test (DAET): Development of a tool to investigate students' ideas about engineers and engineering." In ASEE Annual Conference and Exposition, vol. 2004

[29] B. Fralick, J. Kearn, S .Thompson, \& J.Lyons. "How middle schoolers draw engineers and scientists." Journal of Science Education and Technology 18, no. 1 (2009): 60-73.

[30] M. Klawe, "Increasing female participation in computing: The Harvey Mudd College story." Computer 46, no. 3 (2013): 56-58.

[31] Harvey Mudd College Course Descriptions. https://www.cs.hmc.edu/program/coursedescriptions [Accessed January 31, 2019].

[32] Bureau of Labor Statistics News Release, September 20, 2018. "Employee Tenure Statistics," https://www.bls.gov/news.release/tenure.nr0.htm [Accessed January 31, 2019].

[33] "Gender Equality and Development 2012," The World Bank, Chapter 5, Page 32, https://siteresources.worldbank.org/INTWDR2012/Resources/77781051299699968583/7786210-1315936222006/Complete-Report.pdf [Accessed January 31, 2019]. 
[34] “The State of the Gender Pay Gap 2018," PayScale, https://www.payscale.com/hr/genderpay-gap

[35] National Center for Education Statistics, https://nces.ed.gov/

[36] D. A. Koonce, J. Zhou, C. D. Anderson, D. A. Hening, \& V. M. Conley. "What is STEM?." In American Society for Engineering Education. American Society for Engineering Education, 2011.

[37] L. H. Loewu, "When Did Science Education Become STEM?" Education Week, April 2, 2015,https://blogs.edweek.org/edweek/curriculum/2015/04/when did science education becom e_STEM.html [Accessed January 31, 2019].

[38] H. B. Gonzalez, \& J. J. Kuenzi. "Science, technology, engineering, and mathematics (STEM) education: A primer." Congressional Research Service, Library of Congress, 2012. https://fas.org/sgp/crs/misc/R42642.pdf [Accessed January 31, 2019].

[39] United States Immigration and Customs Enforcement. "STEM Designated Degree Program List Effective May 10, 2016"

https://www.ice.gov/sites/default/files/documents/Document/2016/stem-list.pdf [Accessed January 31, 2019].

[40] National Research Council. Research training in the biomedical, behavioral, and clinical research sciences. National Academies Press, 2011. Appendix C.

https://grants.nih.gov/training/research_training_biomedical.pdf [Accessed on January 31, 2019].

[41] Y. Xie, M. Fang, \& K. Shauman. "STEM education." Annual Review of Sociology 41 (2015): 331-357

[42] S. E. Lopez, \& W. H. Goodridge. "The State of Engineering Integration in K-12 Science Standards: Five Years After NGSS (Fundamental)." In 2018 ASEE Annual Conference \& Exposition. 2018.

[43] D. Seehorn, \& L. Clayborn. "CSTA K-12 CS Standards for All." In Proceedings of the 2017 ACM SIGCSE Technical Symposium on Computer Science Education, pp. 730-730. ACM, 2017.

[44]_ComputerScience.Org, "Women in Computer Science: Getting Involved in STEM," https://www.computerscience.org/resources/women-in-computer-science/. [Accessed on January 31, 2019].

[45] B. Andrei. "Pilot CS $+\mathrm{X}$ joint major program concludes second year" The Stanford Daily, May 31, 2016. https://www.stanforddaily.com/2016/05/31/pilot-csx-joint-major-programconcludes-second-year/ [Accessed January 31, 2019]. 
[46] B. Quilantan. "Should Colleges Let Ailing Majors Die or Revamp Them," The Chronicle of Higher Education, May 20, 2018. https://www.chronicle.com/article/Should-Colleges-LetAiling/243447?cid $=$ cp202 [Accessed January 31, 2019].

[47] A. J. Ko. "A visit to Northwestern University: CS for All, CS+X, and interdisciplinary learning," Medium, October 30, 2017 https://medium.com/bits-and-behavior/a-visit-tonorthwestern-university-cs-for-all-cs-X-and-interdisciplinary-learning-2d4b56fe709b [Accessed January 31, 2019].

[48] University of California, Berkeley, Division of Data Sciences. “UC Berkeley's Data Science Major Takes Off” https://data.berkeley.edu/news/uc-berkeleys-data-science-major-takes [Accessed January 31, 2019]

[49] University of British Columbia, "Juliette Link: Computer Science," https://students.arts.ubc.ca/student-juliette-link-computer-science/] [Accessed January 31, 2019]

[50] J. J. Heible. "Breaking the Gender Barrier in Engineering," Scientific American: Voices Blog December 21, 2016, https://blogs.scientificamerican.com/voices/breaking-the-genderbarrier-in-engineering/\#googDisableSync [Accessed January 31, 2019].

[52] E. Shao \& E. Wan, "CS+X major program to no longer accept new students," The Stanford Daily, January 23, 2019 https://www.stanforddaily.com/2019/01/23/csx-major-program-to-nolonger-accept-new-students/[Accessed January 31, 2019].

[53] P. Monahan. "How SF State is working to change the face(s) of computer science," SF State News Release, December 21, 2018, https://news.sfsu.edu/news-story/how-sf-state-workingchange-faces-computer-science [Accessed January 21, 2018].

[54] Center for the Advancement of Women in Technology. "New "Technology Pathways Initiative" Tackles the U.S. Tech Workforce Crisis" https://www.cawit.org/new-technologypathways-initiative-tackles-the-u-s-tech-workforce-crisis/ [Accessed January 31, 2019]

[55] National Science Foundation Award 1841563 "EAGER:X+CS: CS Pathways for Non CS majors"

https://www.nsf.gov/awardsearch/showAward?AWD_ID=1841563\&HistoricalAwards=false. [Accessed January 31, 2019].

[56] S. C. Olhede \& Patrick J. Wolfe. "The future of statistics and data science." Statistics \& Probability Letters 136 (2018): 46-50.

[57] V. Ortiz-Repiso, J. Greenberg, and J. Calzada-Prado. "A cross institutional analysis of data-related curricula in information science programmes: A focused look at the iSchools." Journal of Information Science (2018): 0165551517748149.

[58] MIT News. "MIT reshapes itself to shape the future," October 15, 2018 http://news.mit.edu/2018/mit-reshapes-itself-stephen-schwarzman-college-of-computing-1015 
[Accessed January 31, 2019].

[59] UTSA Today. "UTSA expands Downtown Campus with a National Security Collaboration Center and planned new School of Data Science," September 6, 2018.

https://www.utsa.edu/today/2018/09/story/NSCC_SDS-announcement.html [Accessed January 31, 2019].

[60] Georgia Institute of Technology. "Core Requirements by Major," https://admission.gatech.edu/transfer/course-requirements-major [Accessed January 31, 2019]

[61] USNA News Center. "Naval Academy Cybersecurity Program Receives ABET Accreditation,"

September 21, 2018

https://www.usna.edu/NewsCenter/2018/09/NAVAL\%20ACADEMY\%20CYBERSECURITY\% 20PROGRAM\%20RECEIVES\%20ABET\%20ACCREDITATION.php

[Accessed January 31, 2019]

[62] F. Bruni. “Aristotle's Wrongful Death,” NY Times, May 26, 2018

https://www.nytimes.com/2018/05/26/opinion/sunday/college-majors-liberal-arts.html. [Accessed January 31, 2019]. 